\title{
pnmbalina
}

(8)

\section{Educação, Corpo, Cultura: caminhos possíveis para a Humanização e a Educação de Jovens e Adultos}

\author{
Autor(es): $\quad$ Silva, Maria Cecilia de Paula \\ Publicado por: Imprensa da Universidade de Coimbra \\ URL \\ persistente: URI:http://hdl.handle.net/10316.2/41301 \\ DOI: $\quad$ DOI:https://doi.org/10.14195/978989 26 1326-0_12 \\ Accessed : $\quad$ 26-Apr-2023 11:14:40
}

A navegação consulta e descarregamento dos títulos inseridos nas Bibliotecas Digitais UC Digitalis, UC Pombalina e UC Impactum, pressupõem a aceitação plena e sem reservas dos Termos e Condições de Uso destas Bibliotecas Digitais, disponíveis em https://digitalis.uc.pt/pt-pt/termos.

Conforme exposto nos referidos Termos e Condições de Uso, o descarregamento de títulos de acesso restrito requer uma licença válida de autorização devendo o utilizador aceder ao(s) documento(s) a partir de um endereço de IP da instituição detentora da supramencionada licença.

Ao utilizador é apenas permitido o descarregamento para uso pessoal, pelo que o emprego do(s) título(s) descarregado(s) para outro fim, designadamente comercial, carece de autorização do respetivo autor ou editor da obra.

Na medida em que todas as obras da UC Digitalis se encontram protegidas pelo Código do Direito de Autor e Direitos Conexos e demais legislação aplicável, toda a cópia, parcial ou total, deste documento, nos casos em que é legalmente admitida, deverá conter ou fazer-se acompanhar por este aviso.

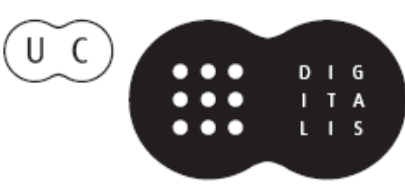




\section{2. EDUCA ÇÃ O, CORPO, CULTURA：CAMINHOS POSSÍVEIS PARA A HUMANIZAÇÃO E A EDUCAÇÃO DE JOVENS EADULTOS}

Maria Cecilia de Paula Silva ${ }^{36}$

\section{Resumo}

Artigo busca refletir sobre as questões da educação na perspectiva do corpo e da cultura como meios possíveis para a humanização no tempo presente, em que as condições de vida se tornam preocupantes para o futuro da humanidade. O foco está na investigação das possibilidades de se pensar a educação como questão política e meios para a transformação social e econômica para uma sociedade mais justa e igualitária. Neste ínterim, o potencial expressivo e criativo de expressões corporais, culturais e possibilidades de perspectivas educacionais que possam patrocinar o desenvolvimento humano para a emancipação. Trata-se de uma investigação no território dos processos educacionais em si, no universo do signo e dos significados históricos de práticas sociais, culturais, corporais

36 Professora Doutora do PPGE/ Faculdade de Educação/ Universidade Federal da Bahia/ BR, coordenadora do grupo de pesquisa HCEL, certificado pelo CNPq e da Linha Educação, cultura corporal e lazer do PPGE/UFBA. Bolsista CAPES Processo BEX 6990/14-2. Estágio Sênior na Université de Strasbourg (2015-2016). Pós-doutorado Université Strasbourg (2011-2012). 
e sua discussão no meio educacional. Constitui uma pesquisa histórica do tempo presente, em andamento, baseada nos princípios da educação defendidos por Freire (2000, 2001). A linguagem corporal é aqui compreendida como o maior potencial expressivo do meio social que pertence a nossa realidade histórica e, por este motivo, nos interessa. A análise cultural dos signos corporais pelos princípios da história do tempo presente será realizada focando o corpo jovem da periferia de Salvador/BA (Brasil) e sua relação com os sentidos e significados históricos sociais e culturais, destacando a linguagem corporal e seu potencial expressivo no tempo presente, advindos da periferia de Salvador/BA e suas relações com uma educação para a emancipação.

\section{Abstract}

This paper aims to reflect on the education in the perspective of body and culture as possible ways to humanization in the current days, when life conditions become a concern in the future of humanity. The focus is in the investigation of the possibilities of thinking about education as a political issue and a mean to a social and economic transformation towards a more just and egalitarian society. Meanwhile, the expressive and creative potentials of corporal and cultural expressions may lead to educative practices that enable the human development with aim of emancipation. This is an investigation in the field of educational processes, in the universe of sign and the historical meanings of social, cultural and corporal practices and their discussion in the educational area. It is about a historical enquiry in the present time, in progress, based on the educational fundaments supported by Freire $(2000,2001)$. The body language is here understood as the 
most expressive potential of our historical reality and, for this reason, of interest to us. The cultural analysis of the corporal signs through the principles of present times' history will be held focusing the young body from the outskirts of Salvador/BA (Brazil) and its relation with the historical and social meanings, highlighting the body language, its expressive potential and its relationship with the education for human emancipation. 


\section{Introdução}

Este artigo reflete sobre a educação, o corpo e a cultura como meios possíveis para a humanização em tempos em que as condições da vida estão em questão em função de crises, no âmbito social, econômico, ambiental, político, religioso, sexual, entre outros. O foco principal está na investigação das possibilidades de se pensar a educação como questão política e meios para a transformação social e econômica para uma sociedade mais justa e igualitária. Neste ínterim, o potencial expressivo e criativo de expressões corporais, culturais e possibilidades de perspectivas educacionais que possam patrocinar o desenvolvimento humano para a emancipação se tornam relevantes. Trata-se de uma investigação no território dos processo educacionais em si, no universo do signo e dos significados históricos, sociais, culturais, a partir da imagem e oralidade de práticas corporais e sua discussão no meio educacional. Constitui uma pesquisa histórica do tempo presente, em andamento, baseada nos princípios da educação defendidos por Paulo Freire. A escolha metodológica foi assim determinada por compreendermos que a história do tempo presente abarca melhor as expectativas do objeto investigado. Foi privilegiado o eixo da linguagem corporal por dois motivos principais: porque buscávamos as especificidades culturais, selecionadas por meio de sua expressão histórico-cultural. A segunda razão é porque entendemos ser na sintaxe corporal que se encontra o maior potencial expressivo humano e comunicacional, a linguagem universal capaz de ligar povos de línguas faladas e escritas muito diferenciadas e de conseguirem estabelecer diálogos, se fazerem entender. Portanto, a linguagem corporal compreendida como o maior potencial expressivo do meio social que pertencem à nossa realidade histórica e, por este motivo, nos interessam. A análise cultural dos signos corporais pelos princípios da história do tempo presente, no caso específico, do corpo negro da juventude da periferia de Salvador. Os atributos 
específicos dos meios de produção de sentidos e significados foram reconhecidos em função da classificação apontada pela mídia local. À guisa de conclusão, destacamos a linguagem corporal e seu potencial expressivo no tempo presente, por meio de significados históricos e culturais advindos da periferia de Salvador/Ba, relações com uma educação pautada nas contribuições de Paulo Freire e perspectivas educacionais orientadas para a emancipação.

Esta é nossa intenção: dialogar, a partir de elementos centrais da educação, corpo e cultura buscando encontrar caminhos possíveis para a Humanização e olhar a educação de jovens e adultos para a emancipação. Importante focar os corpos e as histórias nas quais esses corpos são utilizados, expostos, narrados ou atacados, tendo em mente que ao nível semiótico nunca é apenas o corpo de um indivíduo que é abordado, mas também o exercício do poder e o poder em si. Além de Freire (2000, 2001), estaremos acompanhados de Hobsbawm (2007), Hesse (2011), Brandão (1995), Benjamin (1991, 2013), Silva (2009), Said (2007, 2011), Judt (2011), Tragtenberg (2010).

\section{Para situar o tempo e o espaço}

A exploração e a dominação dos seres humanos, como indivíduos e como classes, negados no seu direito de estar sendo, é imoralidade das mais gritantes (Freire, 2000, p.45).

Século XXI. Planeta Terra. Tempos globalizados. Máximos. Tecnologias ultra; ciências puras; Corpo esportivo de alto rendimento. Talentos mil. Prêmios Nobel destacando-os anualmente. Iluminações incríveis. Explosões: de som, de riqueza, de glórias,

de bombas também. Megaeventos. Copas, shows, carnaval, fute- 
bol, Olimpíadas, jogos Olímpicos. Outros espaços de encontro, vida, educação: shoppings e mundo virtual. Mensagens passadas quase à velocidade da luz rodam o mundo em todo o segundo. Mundo veloz. Mas, atenção, pois este é um retrato meio borrado de nosso tempo presente.

Borrado porque, neste retrato o fundo do pano fica ao largo. Miséria, penúria, guerra, terrorismo, a dor e a fome. Ignorâncias do homem. Desigualdades econômicas e sociais saltam aos olhos. Corpos gravados pela dor. Corpos que gritam nas ruas, corpos que vagam perdidos, corpos que lutam, nadam, afogam. Corpos fugidios tentando escapar de guerras, de traumas, terremotos, furacões. Desumanização. Eric Hobsbawm (2007) nos apresenta alguns temas de nosso século, como a migração em massa, a xenofobia, a identidade nacional e cultural. Esse autor ressalta que este tempo, que se convencionou denominar de globalização, não pode ser compreendido como um tempo de divisão internacional igualitária, política, econômica e militar entre os diversos países. Isto porque os processos de intercâmbio do comércio, da informação, da cultura e das finanças são organizados por novas e desiguais formas de relação ente países.

$\mathrm{E}$, nesse tempo, os Estados Unidos da América assumem uma centralidade por seu peso na economia mundial, impactando em todos os grandes indicadores econômicos, para além de seu inconteste poderio militar nos séculos XX e XXI. Para este autor, o "império" norte-americano necessita operar em todo o globo, não por meio de um colonialismo clássico, mas mediante países dependentes e satélites, com ou sem o apoio de governantes eleitos.

Estas ações vem se alastrando. Os exemplos são inúmeros. As possibilidades de compreender a perversidade humana que espraia no século XXI. Em todos os lugares do mundo. Da primavera árabe ao horror da Síria atual. No Brasil, corpos em luta. Muitos vão as ruas reivindicando mudanças. Na Europa, há o temor 
de ataques terroristas. Em África, o clamor dos povos pela paz e batalhas sangrentas em muitos paises marcam o continente de sangue. Terremotos arrasam comunidades, cidades, países, como Haiti, Japão, Chile, China, Nova Zelândia, etc. A terra treme em outros lugares do mundo também, de formas várias. Esgotou-se o tempo do bem estar social.

Início de 2013. Noticias de jornal: Um navio naufragou, em terras italianas. Velhos, jovens, crianças, homens, mulheres africanos tentando chegar ao sul da Sicília, e, no continente italiano, mesmo sendo ilegais, perseguidos, desprezados intencionavam conquistar uma vida digna. Ou, ao menos uma vida que se possa sobreviver. Ao invés disso/ em menos de três dias, dos aproximadamente 550 que partiram da Costa norte-africana (maior parte de Eritréia e Somália). Os mortos chegam a trezentos. Séculos atrás os navios negreiros saiam do continente africano a caminho do inusitado. Situação causada por uma condição de escravidão inumana, ou, no sentido aqui considerado, uma condição de humanização que transformava o ser humano em escravizado. Em Navio Negreiro - tragédia no mar, Alves (1947) retrata a situação vivida pelos africanos no mar àquela época quando, acorrentados, viviam um horror - humano horror, descrito em versos pelo autor.

Era um sonho dantesco... o tombadilho

Que das luzernas avermelha o brilho.

Em sangue a se banhar.

Tinir de ferros... estalar de açoite...

Legiões de homens negros como a noite,

Horrendos a dançar...

Negras mulheres, suspendendo às tetas

Magras crianças, cujas bocas pretas

Rega o sangue das mães: 
Outras moças, mas nuas e espantadas,

No turbilhão de espectros arrastadas,

Em ânsia e mágoa vãs!

Reclamava-se aos céus, suplicando o fim da perversidade humana contra o povo africano e à condição humana (ou desumana?) a que estavam expostos:

Senhor Deus dos desgraçados!

Dizei-me vós, Senhor Deus!

Se é loucura... se é verdade

Tanto horror perante os céus...

ó mar! por que não apagas

Co'a esponja de tuas vagas

De teu manto este borrão?...

Astros! noite! tempestades!

Rolai das imensidades!

Varrei os mares, tufão!...

Há séculos atrás a diáspora africana apontava um caminho de desumanização. Em 2013, a diáspora africana continua apontando caminhos de desumanização dos seres humanos, apesar do modo de produção escravista ter se encerrado (oficialmente) tempos atrás.

Paulo Freire (2000, p.45), questionava a explicação dada pelos governos sobre os motivos da miséria, da dor, da fome, da ignorância, da enfermidade crônica, que dizam "cinicamente, que o mundo é assim mesmo; que uns trabalham mais, com competência, por isso têm mais e que é preciso ser pacientes pois um dia as coisas mudam”.

A paciência parece estar se esgotando. Manifestações crescentes, greves, lutas, revoltas, guerras, revoluções são passos importantes que definem um momento diferenciado. Passo importante, mesmo 
fundamental em tempos atuais. Possíveis de nos mostrar alguns caminhos. Hessel (2011), militante da resistência francesa publica o manifesto Indignai-vos, em que sugere a indignação como a primeira forma de resistência para alterar algo. Na apresentação da obra de Freire (2000), Pedagogia da indignação: cartas pedagógicas e outros escritos, a organizadora comenta que precisamos nos atualizar na leitura crítica de Freire no tempo presente para alimentarmo-nos de esperança para sonharmos os inéditos viáveis de hoje e as necessárias transformações sociais para concreta justiça, equidade, paz no futuro.

\section{Da educação, da cultura, do lugar}

Brasil. Nordeste. Salvador. Localização importante para situar essa discussão que o artigo propõe: dialogar sobre o corpo, a cultura e a educação e possíveis caminhos de Humanização em tempos que caminham para uma desumanização. Em tempos de globalização e de crise do capital, de mais uma das inúmeras crises desde o seu surgimento. Época de grandes realizações humanas, de perspectivas de desenvolvimento humano imensuráveis.

No entanto, a desigualdade económica e social instalada na sociedade nos diz muito mais. Esta conformação do estar no mundo, em que se considera natural o desperdício da alimentação. É vergonhoso observar que enquanto milhares morrem de doenças decorrentes de superalimentação, muitos outros vivem com problemas crônicos decorrentes da subalimentação; populações inteiras morrem de forma violenta: de desnutrição, de fome, de miséria. Morrem diariamente por não terem o que comer.

Em outros lugares no mundo e em muitos do Nordeste do Brasil, muitas mulheres são diariamente violentadas. Muitos outros discriminados. Outros ainda vitimados. Em Salvador, a população negra e 
indígena continua a sofrer inúmeros preconceitos. Diuturnamente. Não somente em Salvador. A discriminação, o preconceito, o atentado aos direitos humanos e à vida são inúmeros e estão presentes em todas as partes do mundo. Estas são formas de desumanização presentes na vida cotidiana.

Em sua obra, Em campo aberto, Brandão (1995, p.84) reflete sobre a dificuldade do educador em pensar em perspectivas culturais emancipatórias utilizando-se a prática pedagógica, ao se consagrar o sentido social da cultura "por uma visão que reduz a cultura a costumes, tradições, práticas e condutas inventariadas - com a língua, os ritos e os cultos, a tradição mitológica e as produções materiais de tecnologias, arte e artesanato, assim como conjuntos acabados de visões do mundo, ordenados como sistemas de mitos e crenças, literaturas, ou religiões". Isto porque nesta forma de se compreender a cultura domina uma realidade dada e outorgada ao conjunto dos cidadãos na sociedade. Ou seja, como um produto feito, uma consagração dos modos de ser e de viver regidos por critérios de tradicionalismo, estabilidade e atemporalidade.

Para o autor, é por este ponto de vista rígido, consagrado, que o sentido social da cultura que se perde seu traço mais importante, de ser um processo na história das relações entre os seres humanos e os grupos com seus ambientes naturais, do significado das trocas entre os seres humanos entre si e com os outros, de formas diversas, múltiplas, permanentes.

É preciso compreender a cultura na sua forma particular em que os grupos sociais reproduzem suas condições de vida em sociedade e de formas de viver dos sujeitos históricos com códigos definidos, de regras, princípios, atribuindo sentidos e significados às suas experiências; "sistemas de crenças, valores, visões do mundo e identidade social, étnica, sexual, profissional, etc." (Brandão, 1995, p.85). Said (2011, p. 307) acrescenta que o contato com a cultura envolve a reflexão sobre a dominação e a apropriação pela 
força. O "resultado líquido do intercâmbio cultural entre parceiros cientes da desigualdade é que o povo sofre".

Ao registrar o cunho político da educação Freire (2001, p.34) afirma que, certamente, há uma imoralidade imensa, radical "na dominação, na negação do ser humano, na violência sobre ele, que contagia qualquer prática restritiva de sua plenitude e a torna imoral também". E continuamos com o autor compreendendo que Imoral é a dominação econômica, é a dominação sexual, é o racismo, é a violência dos mais fortes sobre os mais fracos. Imoral é o mando das classes dominantes de uma sociedade sobre a totalidade de outras, que dela se torna puro objeto, com maior ou menor dose de conivência.

Em pedagogia da indignação, Paulo Freire nos chama a atenção para o necessário momento de indignar-se. Indignar-se contra as desigualdades escancaradas a céu aberto, pois não se educa se não tivermos a capacidade de nos indignar diante de qualquer injustiça. Esta, de certa forma é também a conclamação de Hesse (2011) em seu manifesto: Indignai-vos! como a saída possível da situação atual. Precisamos continuar a luta, precisamos nos movimentar e a indignação é uma das primeiras formas de tomarmos consciência desse momento histórico.

Compreendemos o que está em destaque nestas obras e que este evento, em especial, busca debater são processos humanos, ou de humanização.

Processos estes culturais, portanto, educacionais. Mas, o que estamos entendendo por cultura e por educação? Importa situar a cultura em uma prática que aponta para a emancipação humana, ou, nos termos aqui considerados, para a humanização não desumanizada. Importa compreendermos o sentido da educação em devir, porque o mundo não é necessariamente isto ou aquilo, "porque os seres humanos são tão projetos quanto podem ter projetos para o mundo" (Freire, 2001,p.20). 
Para ele, tanto a cultura como a história são feitas pelas manifestações do exercício da liberdade (por meio da criatividade, inovação, curiosidade), que, quando negada necessita de uma luta por ela, mesmo que esta luta implique em correr riscos. Esta seria um dos fins da educação: criar no sujeito a consciência de que a presença no mundo é um fator de risco, e isto não é ruim. E a educação, numa perspectiva da emancipação, deve proporcionar o assumir riscos, lutar pelo que acredita e, ir a cada momento tornando maior consciência da capacidade de intervenção no mundo. Tornar-se sujeito que compreende o mundo como devir, em que a mudança faz parte da cultura, e que cada um tem a possibilidade de entende-la, aceitá-la, negá-la, alterá-la como ser politico, coletivo e individual.

O acomodar-se, ainda de acordo com o autor, é desistir da luta para transformar o mundo. A educação para a emancipação impõe uma atitude de não se acomodar; torna-se imprescindível correr riscos, portanto, posicionar-se de forma permanente por justiça e ética. A dominação está associada de forma direta à acomodação e o educador, e a educação deve aí intervir para impedir que situações de opressão continuem. Para tal, a aprendizagem deve ser de mundo. Neste sentido, a educação deve ser compreendida como o trabalho vivo da experiência social, cultural, corporal.

\section{Educação, corpo e cultura: imagens e imaginações.}

Walter Benjamin (2013), a seu tempo alerta para a situação do capitalismo entendido como religião, bem como para o perigo de uma compreensão linear da história. Nossa tentativa é de aprofundarmos um pouco esta discussão no âmbito educacional. Para isso, situaremos o Nordeste do Brasil, locus de nosso estudo e sua 
perspectiva cultural quando falamos de corpo, mais especificamente de corpo adjetivado: adolescentes e jovens adultos de maioria advinda da classe pobre, de cor negra, de bairros periféricos de Salvador. Para tal, reportamo-nos para notícias sobre direitos humanos. A reportagem de Araújo (2015) destaca: "mais três jovens morrem assassinados em Salvador em operações da Polícia Militar da Bahia. Neste final de semana, 15 jovens negros foram mortos. A reportagem intitulada "Mais três morrem em ações da PM em Salvador. São 15 mortos desde $6^{a}$ feira" anuncia bem mais que isto. Ela sugere-nos o quadro atual do que acontece em periferias urbanas de grandes cidades no Brasil e que muitos estudiosos apontam como sendo algo próximo (senão exato) a uma faxina étnica, ou conforme a reportagem anuncia "um genocídio contra a juventude negra, um problema que a juventude negra enfrenta há muito tempo e que tem sido combatido por diversos movimentos". Uma das ações é fazer e aprovar leis que inibam ações do próprio Estado que atentam contra parte da população. Mas qual parte? Uma específica, identificada corporal e culturalmente?

A metáfora "o corpo é um Instrumento de medição, identificação", remete-nos a capacidade de classificarmos os seres humanos por marcações específicas, como parte de uma operação que resulta, de forma subsequente, em quantificação. Neste uso metafórico, o elemento "corpo" pode marcar uma quantidade, ou ainda, uma avaliação indicativa de uma situação. Nesta reportagem destaca-se o quantitativo de seres humanos, jovens, negros, de bairros periféricos em Salvador, mortos pelo poder do Estado - policiais militares. E sem razões cabíveis sequer, para prendê-los, segundo testemunhas dos acontecimentos. Esta questão social que nos choca está a acontecer a todo o tempo em Salvador, Bahia, Nordeste do Brasil. Os corpos da reportagem anunciada fala-nos mais do que simples contas numéricas. Estes 15 corpos vão muito além dos aspectos medidos e quantificáveis. Conceitos que perpassam pela 
realidade de compreender o corpo através de imagens emprestadas do corpo. Pela cultura. Devemos pensar, como Guiraud (1980, p.3), que "falamos com nossos corpos".

Minha análise vai girar em torno de duas questões: quais são os elementos culturais seleccionados, em outras palavras, salientados? Por que eles estão inseridos nesta questão? Estaremos dialogando no sentido de questionar a importância da compreensão desse corpo situado social, cultural e historicamente e caminhos possíveis para uma educação de jovens e adultos para a emancipação dialogando com escritos de Freire.

O corpo aqui considerado é o corpo atual, este, das relações de conflito e de poder expressas nas imagens que a atualidade nos traz, como, por exemplo, os conflitos visibilizados mundo afora, no tempo presente. Conflitos políticos expressos pela linguagem corporal. O corpo - sujeito - de reivindicações e ações que envolvem atitudes de resistência, ação, confronto. O corpo chega a ser a arma utilizada pela população em contraposição ao armamento do Estado, ora representado pelo Exército, ora pela Polícia, no Brasil e no mundo. Aqui não se separa o corpo do sujeito, apesar de toda uma história de separação corpo/sujeito, dos tempos da dualidade corpo/alma, tão colado na cultura ocidental.

$\mathrm{O}$ que se coloca em questão é a visibilidade do corpo como forma de estar no mundo e se relacionar cotidianamente, resultado de articulações entre imagens, palavras e outras informações do meio. Ou seja, a necessidade de humanização das relações humanas. Imediata retomada da lógica humanizadora e, neste aspecto a educação interliga-se de forma crucial. Uma educação que, conforme situa Paulo Freire, atenta a complexidade da vida, uma educação integral do sujeito em seu meio e com os demais. Portanto, uma educação que se comprometa com o mundo dos valores, com o mundo do trabalho e com o ambiente de forma geral (o planeta). Para este autor, o processo de humanização requer a construção 
de uma ética universal do ser humano. E requer estarmos situados, engajados, indignarmos para agirmos.

No exercício de situar a importância da educação como ato de transformação, o autor aponta-nos a necessidade de pensarmos a história em movimento, não como repetição do passado ou como algo inexorável, mas como devir, como possibilidade e mais, como necessidade de lutarmos para construí-la. Afirma a necessidade de compreendermos a natureza política da educação em geral, de adultos e da alfabetização, em particular. "jamais pude pensar a prática educativa, de que a educação de adultos e a alfabetização são capítulos, intocada pela questão dos valores, portanto da ética, pela questão dos sonhos e da utopia, quer dizer, das opções políticas, pela questão do conhecimento e da boniteza, isto é, da gnosiologia e da estética"(Freire, 2000, p. 40).

Ele nos chama a atenção para a prática educativa estar atrelada às condições concretas no tempo-espaço em que é realizada, justificando pela forma como ele entende a nossa presença no mundo como seres humanos e nossas relações com a história e a cultura: "por isso, não temo dizer que a educação de adultos hoje, como a educação em geral na perspectiva progressista, tanto quanto ontem e por novas razões também, tem que continuar lutando contra as ideologias fatalistas" (Freire, 2000, p. 43).

Silva (2009, p.23) neste mesmo sentido, aponta-nos a responsabilidade da educação e a necessidade de uma "reflexão critica sobre o (des) trato do corpo no chão da escola torna-se indispensável à reestruturação do seu trato, possibilitando uma educação comprometida com a leitura da realidade e com as possibilidades de sua transformação". Para tal reflexão, a autora sugere conceber o ser humano de forma relacional, de relações ativas, individuais e coletivas. Eis o desafio. O significado de pensarmos em fazer a educação diferente e de fato considerarmos o corpo sujeito histórico, para além dos limites impostos, dos pesos e medidas, das marcas 
tatuadas. Freire levanta a seguinte questão: "Se é possível obter água cavando o chão, se é possível enfeitar a casa, se é possível crer desta ou daquela forma, se é possível nos defender do frio ou do calor, se é possível desviar leitos de rios, fazer barragens, mudar o mundo que não fizemos, o da natureza, por que não mudar o mundo que fazemos, o da cultura, o da história, o da política?" (Freire, 2000, p.44).

Como desafios para uma ação educacional de jovens e adultos diferenciada é que caminham perspectivas de ação pedagógica e investigação educacional desenvolvidas pelo grupo de pesquisa HCEL - PPGE/ FACED/UFBA. A perspectiva proposta é a alteração de compreensão do saber escolar e da assunção do sujeito histórico, social, cultural no diálogo educacional, no saber escolar. Partimos da realidade vivida pelos adolescentes e adultos do ensino médio que frequentam escolas públicas, do Estado da Bahia e Federal, considerando as lógicas sociais e o mundo do trabalho, interpretando-as no tempo presente, no contexto apresentado, no ambiente de contrastes e conflitos. Neste ponto, compreendemos que a questão central de uma educação que busca a conscientização, a emancipação humana visando a transformação social deve valorar a expressão corporal como linguagem, tratando-a em uma perspectiva da totalidade para os estudantes de ensino médio, partícipes da juventude baiana, possibilitando-os de compreender a singularidade do ser social e, ao mesmo tempo, a sua complexidade - corporal, cultural, histórica.

Com relação a questão a complexidade e a unidade na diversidade Freire (2001) dialoga com as diferenças interculturais e seus cortes: de classe, de raça, de gênero e, como alongamento destes, de nações, que geram ideologias, tanto discriminatórias como de resistência. Considera que o que gera ideologia discriminatória é a cultura hegemônica e a cultura discriminada gera, por sua vez, ideologia de resistência (que por sua luta se alternam em diversas: pacíficos, rebeldes, violentos ou voltados para a recriação do 
mundo). E, por serem dialéticos elas se interpenetram, sendo impossível compreendê-las de forma pura ou destituídos de análises das ideologias e de suas relações com o poder. As ideologias "se expressam na linguagem - na sintaxe e na semântica-, nas formas concretas de atuar, de escolher, de andar, de vestir, de até dizer olá, na rua" (Freire, 2001, p.18).

\section{E de como se entrelaçam vida, cultura, corpos: das imagens às imaginações}

Para Benjamin (2013), as imagens são relações sociais que descrevem e legitimam os territórios da ação política, por um lado. Por outro, os corpos e os discursos envolvidos na visualização do poder articulam diferentes níveis de dominação ideológica e de imaginação social. O debate sobre humanidade ou desumanidade no tempo presente pressupõe igualmente uma dimensão corporal ligada à imagem, à dimensão corporal das figuras políticas, ou seja, como as mesmas se apresentam no contexto da encenação não só social, mas também, educacional.

Quanto às imagens e imaginações, Verón, teórico argentino nos auxilia a reflexão no campo do discurso, das relações e da comunicação. Argumenta que a teoria do discurso se baseia em uma dupla questão: a primeira é que "Toda produção de sentido é necessariamente social: não se pode descrever e nem explicar satisfatoriamente um processo significante, sem explicar as condições de produção da vida social". O segundo aporte teórico de sua teoria é que "Todo fenômeno social é, em uma de suas dimensões constitutivas, um processo de produção de sentido, qualquer que seja o nível de análise do micro ou macro sociólogo".

Para Verón, é na semiose que a realidade social é construída. Por menor que seja um ato individual, ele é parte de um quadro 
socializado e estruturação de unidades socializadas das pulsões. Neste sentido, toda produção de sentido possui uma manifestação material. Esta materialidade do sentido define a condição essencial, o ponto de partida necessário de todo estudo empírico sobre a produção de sentido. Qualquer que seja o suporte material, o que chamamos de um discurso ou um conjunto discursivo é uma configuração espaço-temporal de sentido. Isso define o sentido essencial da materialidade, o ponto de partida para estudos sobre a produção de sentido. Seja qual for o material de apoio, geralmente denominado de um discurso ou discurso social, é uma significação espaço-temporal. Um significado que passa pelos elementos fundantes deste texto: o corpo, a cultura e a educação.

Benjamin (2003) considera que as imagens não se resumem a simples objetos, e sim meio e matriz de sua concepção teórica. Como teórico e filósofo da arte de seu tempo, o século XX em plena transformação, Benjamin, apresenta a imagem como elemento fundamental para a reflexão e apreensão do mundo, para além da dos elementos de forma e conteúdo (um terceiro elemento). Em seus escritos ele parece desenvolver uma lógica diferenciada, que nos conduz a pensar em imagens.

As imagens produzem sentidos e significados singulares nos seres humanos. Desde a mais tenra idade, as imagens chamam uma atenção especial e, logo as crianças se encantam com elas e com a expressão das mesmas, gestos, imitações, reflexos, rabiscos e desenhos que vão ganhando formas, conteúdos, histórias fenomenais, etc.

Especificamente, a configuração teórica de Benjamin (2003), ao remeter a esta expressão "pensar em imagens" (Weigel, 1999, p.14), nos aproxima das figuras que se apresentam na realidade em que, muitas vezes, se forja uma tradição de imagens da história que podem nos remeter a pontuar questões como eventuais implicações. As imagens de nossas percepções, idéias e as metáforas que nos 
rodeiam são consideradas como "espaço do corpo e da imagem", lugar em que se gesta a nossa realidade.

Tragtenberg (2010, p.18) insinua que a mecanização do mundo e, por consequência, do ser humano, do corpo, é um anseio do próprio ser humano para, dessa forma, desobrigar-se da responsabilidade de pensar e agir sozinho, garantir sua felicidade, negar o sofrimento e toda a responsabilidade dai decorrentes. Baseia-se nos estudos antropológicos de Dostoievski e na tese segundo a qual o ser humano, "por sua natureza não mecânica, tem dentro de si elementos irracionais não suscetíveis de um tratamento quantitativo, que são a fonte de sua vida". Estes estudos contribuíram para a compreensão de que o ser humano não é uma coisa, mas sim um elemento autônomo: "inerente à natureza humana, essa liberdade não admite limitação de ordem exterior, constituindo a essência do ser".

Observa ainda que a liberdade advém dessa compreensão, liberdade que para o ser humano é uma responsabilidade pesada por pressupor os riscos inerentes, o sofrimento que dá oportunidade ao ser humano de se conscientizar de sua individualidade e de viver a liberdade.

A antropologia humanista por seu turno apresenta-nos a compreensão do ser humano como ser social. Marx inaugura essa compreensão ao desenvolver sua crítica social e tratar de temas relativos à religião, ao Estado e a sociedade. Tragtenberg (2010, p.20) esclarece que para Marx, Estado e sociedade formam um mundo invertido (o Estado e a sociedade produzem a religião que é uma consciência invertida do mundo, já que o Estado e sociedade são um mundo invertido); e as 'deficiências de sua existência' (características humanas) surjam em 'circunstâncias fora de sua vida'. Assim, "a luta de classes nasce de um antagonismo das condições de vida", nasce de uma determinada ação humana, denominada por Marx de deformação da humanidade humana, ou seja, da atividade consciente: "assim como a sociedade produz o homem, ele produz 
a sociedade". A humanidade que produz a autoalienação converte a vida da espécie em meio de sua existência individual.

E essa existência individualizada, essa autoalienação, promove a consideração do outro humano como objeto, instrumento para suas necessidades. Daí decorre a afirmação de que também a sociedade é desumanizada, "assim como o produto do trabalho alienado enfrenta-se com um poder alheio, assim o homem torna-se um poder alheio diante de outro homem; é a característica da sociedade dividida em classes" (Tragtenberg, 2010, p.22).

Silva (2003, p.30) considera que o principal objeto do pensamento filosófico é o ser humano, sua consciência e seu comportamento. Compreendendo que a significação humana e a realidade social não se dissociam é importante considerar estas questões sobre o ponto de vista da totalidade, categoria fundamental no pensamento de Marx, o próprio caráter das expressões dos processos sociais, isto é, um complexo geral estruturado historicamente.

Para Freire, isso não significa negação dos condicionantes a que estamos submetidos - genéticos, culturais, sociais, e sim o reconhecimento de sermos "condicionados mas não determinados; que o condicionamento é a determinação de que o objeto, virando sujeito, se torna consciente. Significa reconhecer que a História é tempo de possibilidade e não de determinismo, que o futuro é problemático e não inexorável".(Freire, 2000, p.51).

Esta é a linha desenvolvida por Freire para fundamentar a lógica educacional, pois para este autor, "a matriz da esperança é a mesma da educabilidade do ser humano: o inacabamento de seu ser de que se tornou consciente"(Freire, p.52). Considera que o ser humano, consciente de seu inacabamento, deve inserir-se em um processo incessante e permanente de busca, de esperança. E este processo é a educação.

Para refletirmos sobre a formação de jovens e adultos no Nordeste do Brasil, Salvador, levando em consideração o contexto social é 
preciso, mais que nunca, fomentar diálogos com teóricos que, como ele, questionam a educação tradicional e apontam perspectivas abertas, caminhos repletos de esperança.

A educação de adultos, segundo Freire (2001) teve o movimento necessário e preponderante, realizado no Brasil na América Latina em direção à educação popular, fato que possibilitou a educação de adultos tornar-se mais abrangente. E esta compreensão passa pela absorção de conteúdos que estabelecessem vínculos com o cotidiano. Para ele "o que acontece, no meio popular, nas periferias das cidades, nos campos - trabalhadores urbanos e rurais reunindo-se para rezar ou para discutir seus direitos -, nada pode escapar à curiosidade arguta dos educadores envolvidos na prática da Educação Popular" (Freire, 2001, p.16). Suas reflexões anunciam que este processo é também político, ao refletir a capacidade de mobilização em direção aos objetivos coletivos, uma militância. Neste sentido, a prática educativa é reconhecida como prática política, e assim, livra-se das prisões da burocracia e de procedimentos escolarizantes. Assim, a educação popular e progressista, "superando o que chamei, na Pedagogia do oprimido, 'educação bancária', tenta o esforço necessário de ter no educando um sujeito cognoscente, que, por isso mesmo, se assume como sujeito (...) são tão importantes para a formação dos grupos populares certos conteúdos (...) quanto a análise que eles façam de sua realidade concreta" (Freire, 2001, p. 17). Para ele, o senso comum só pode ser superado a partir dele, não pelo seu desprezo. O ponto de partida seria, assim, os sonhos, frustações, dúvidas, medos, desejos dos educandos (crianças, jovens, adultos). Insiste ele na necessidade de se trabalhar com palavras e temas situados, palavras e temas grávidos de mundo. Somente assim teria sentido a Educação Popular como facilitadora da compreensão científica que grupos e movimentos poderiam e deveriam experimentar. A compreensão do tempo histórico aberto, dinâmico, feito e refeito por nós é fundamental 
para esta concepção de educação popular que, "praticando-se num tempo espaço de possibilidade, por sujeitos conscientes ou virando conscientes disso, não possa prescindir do sonho (...) É possível a vida sem sonho, mas não existência humana e História sem sonho". (Freire, 2001, p.18).

\section{Apontamentos para outras sínteses e novos diálogos}

Este artigo buscou refletir sobre a educação e os saberes do corpo e da cultura no tempo presente, a partir do diálogo com escritos freireanos. Nossa compreensão é que pensarmos em uma educação para a emancipação humana e a transformação social é necessário considerarmos que o corpo e a cultura figuram como aspectos centrais do processo educacional. Neste sentido, faz-se imprescindivel conhecer e valorizar os saberes locais e as perspectivas históricas, culturais, sociais, estabelecendo conexões com o todo e interpretando-as no tempo presente e no contexto de periferia de Salvador, região Nordeste, Brasil, um contexto complexo, de contrastes e conflitos. A proposição foi dialogar sobre caminhos possíveis de uma educação na perspectiva da emancipação.

Com esta compreensão consideramos importante destacar a dimensão corporal de manifestações políticas, do ontem e do hoje, como se apresentam no contexto da realidade, sob diversos aspectos. Apresentamos uma reflexão a partir de fragmentos de uma dada realidade, uma notícia de jornal que explicita uma realidade contraditória e que aponta para a urgência da humanização das relações sociais, para a compreensão dos direitos humanos e para a necessidade de justiça e equidade econômica e social. Ao dialogar com estudos e perspectivas sobre a "visibilidade" dos "corpos" e relações de poder, entendendo-se o corpo como sujeito, ser histórico, cultural - resultado da articulação social, compreendemos a 
importância do ato de educar, da alfabetização para além das letras, da necessidade de conscientização e compreensão dos contextos para que, apropriando-se deles, possamos transformá-los. Importou compreendermos as imagens, as palavras, as tramas, ideologias e informações colocadas em jogo, bem como as relações de poder.

Este foi o desafio de Paulo Freire e ele permanece um desafio atual. Importou-nos focar a reflexão a partir de um extrato da vida cotidiana, uma das muitas histórias vivenciadas em Salvador por jovens e adultos tão expostos. História que aponta a lógica perversa da sociedade brasileira e expõe a situação da juventude que mora na periferia de Salvador, de corpos negros e pobres, considerando que nunca é apenas o corpo de um indivíduo que é abordado, mas todo o contexto social; não é o caso em si, mas também o exercício do poder e até mesmo o poder do Estado. Este poder que é refletido em cada momento histórico e cultural e, de forma diversa, no corpo social, no corpo individual, no sujeito histórico.

A reflexão das relações e da comunicação baseou-se em uma dupla questão: a de toda produção de sentido é necessariamente social; e todo fenômeno social é, em uma de suas dimensões constitutivas, um processo de produção de sentido, qualquer que seja o nível de análise (do micro ou macro). Acreditamos nessa perspectiva social, de considerar a cultura e corpo como fundamentais para uma educação na perspectiva da emancipação humana, por outra forma de compreender a vida e vivê-la, com justiça econômica, social. Educação, corpo e cultura como caminhos possíveis para a Humanização em tempos que, mesmo humanos, parece-nos cada dia mais desumanizados.

Ao focarmos o corpo e suas expressões históricas, culturais, encontramos maior potencial expressivo humano e comunicacional, uma linguagem universal capaz de ligar povos de línguas faladas e escritas muito diferenciadas e deles, efetivamente, conseguirem estabelecer diálogos, se compreender. A linguagem corporal compreendida como 
o maior potencial expressivo do meio social que pertencem à nossa realidade histórica. Isso define o sentido essencial da materialidade, corporal, o ponto de partida necessário para os necessários estudos referentes à humanização da humanidade.

Os caminhos possíveis são inúmeros e dependem do coletivo envolvido - educadores, gestores, educandos, comunidade -, enfim, seres humanos, sujeitos dessa história aberta que está sendo sempre construída e prenhe de perspectivas. Perspectivas afinadas à compreensão de que educar é antes de tudo um ato político, complexo, amplo e consciente. Prespectivas que afirmam a importância do legado de Paulo Freire na atualidade, por isso o atualizam.

\section{Referências bilbiográficas}

Alves, C. (1947). Poesias escolbidas. Rio de Janeiro: Imprensa Nacional.

Araujo, E. (2015, Fevereiro, 08). Mais três morrem em ações da PM em Salvador. São 15 mortos desde $6^{\circ}$ feira. Ponte: direitos humanos, justiça e segurança pública. Recuperado em 25/03/2015 de http://ponte.org/mais-tres-morrem-em-acoes-da-pm-em-salvador-ja-sao-15-os-mortos-no-final-de-semana/.

Benjamin, W. (2003). Obras escolbidas: magia e técnica, ciência e arte. (3 ${ }^{\mathrm{a}}$ ed., Vol.1.). São Paulo: Civilização Brasileira.

Benjamin, W. (2013a). O capitalismo como religião. São Paulo: Boitempo.

Brandão, C. R. (1995). Em campo aberto: escritos sobre a educação e a cultura popular. São Paulo: Cortez.

Freire, A. M. A. (2000). Introdução. In Freire, P. Pedagogia da indignação: cartas pedagógicas e outros escritos. São Paulo: Editora Unesp.

Freire, P. (2000). Pedagogia da indignação: cartas pedagógicas e outros escritos. São Paulo: Editora Unesp.

Freire, P. (2001). Política e educação: ensaios. (5ª ed.). São Paulo: Editora Cortez.

Hessel, S. (2011). Indignai-vos! Portugal: Editora Objectiva.

Hobsbawm, E. J. (2007). Globalização, democracia, terrorismo. São Paulo: Companhia das Letras.

Guirald, P. (1980). A semântica. (3ª ed.). Rio de Janeiro: Difel.

Said, E. W. (2011). Cultura e imperialismo. São Paulo: Companhia das Letras.

Said, E. W. (2007). Humanismo e crítica democrática. São Paulo: Companhia das Letras.

Silva, M. C. P. (2009). Do corpo objeto ao sujeito bistórico: perspectivas da concepção de corpo na bistória da educação brasileira. Salvador: EDUFBA. 
Santos, B.S. \& Rodriguez, C. (2002). Reinventar a emancipação social para novos manifestos. In Santos, B.S. (Org.). Produzir para viver: os caminhos da produção não capitalista (pp.22-75). Rio de Janeiro: Civilização Brasileira,

Tragtenberg, M. (2010). O capitalismo no século XX. (2 ${ }^{\text {a }}$ ed.) São Paulo: Editora UNESP.

Verón, E. (1998). A produção do sentido. São Paulo: Cultriz.

Weigel, S. (1999). Cuerpo, imagen y espacio en Walter Benjamin: uma relectura. Argentina: Paidós. 